\title{
Multi-institutional survey of carotid body tumors in Japan
}

\author{
AYA IKEDA $^{1}$, KIYOTO SHIGA $^{1}$, KATSUNORI KATAGIRI $^{1}$, DAISUKE SAITO $^{1}$, JUN MIYAGUCHI ${ }^{1}$, \\ SHIN-ICHI OIKAWA ${ }^{1}$, KODAI TSUCHIDA ${ }^{1}$, TAKAHIRO ASAKAGE ${ }^{2}$, HIROYUKI OZAWA $^{3}$, \\ KEN-ICHI NIBU ${ }^{4}$, NAOKI OHTSUKI ${ }^{4}$, YASUSHI FUJIMOTO ${ }^{5}$ and KEN-ICHI KANEKO ${ }^{6}$ \\ ${ }^{1}$ Department of Head and Neck Surgery, Iwate Medical University School of Medicine, Morioka, Iwate 020-8505; \\ ${ }^{2}$ Department of Head and Neck Surgery, Tokyo Medical and Dental University School of Medicine, Tokyo 113-8510; \\ ${ }^{3}$ Department of Otorhinolaryngology-Head and Neck Surgery, Keio University School of Medicine, Tokyo 160-8582; \\ ${ }^{4}$ Department of Otolaryngology-Head and Neck Surgery, Kobe University School of Medicine, Kobe 650-0017; \\ ${ }^{5}$ Department of Otorhinolaryngology, Nagoya University Graduate School of Medicine, Nagoya 466-8560; \\ ${ }^{6}$ Department of Otolaryngology-Head \& Neck Surgery, Nagasaki University School of Medicine, Nagasaki 852-8501, Japan
}

Received September 24, 2017; Accepted December 14, 2017

DOI: $10.3892 / \mathrm{ol} .2018 .7925$

\begin{abstract}
There has been no attempt to clarify the status of patients with carotid body tumor (CBT) in Japan. This multi-institutional survey analyzed patients with CBT throughout Japan by gathering information on these patients from institutions that performed head and neck surgeries. Information from a total of 150 patients from 25 institutions from the past 20 years was employed in the present survey. There were 87 females and 63 males, and their mean age was 48.0 years old. The most common chief complaint was a neck mass and the mean suffering period was 46.1 months. Eighteen patients had a family history of paragangliomas and fifteen patients had bilateral CBTs. Among the 94 patients who underwent surgery to remove a CBT, 23 patients had tumors classified as Shamblin type I, 59 had type II and 12 had type III. The most frequent feeding artery of these CBTs was the ascending pharyngeal artery. Preoperative embolization of these arteries was effective in reducing blood loss; however, the operation time in Shamblin type I and II tumors was not improved. Thus these results revealed the status of patients with CBT and their treatment throughout Japan.
\end{abstract}

\section{Introduction}

Carotid body tumor (CBT) is a rare disease derived from carotid body paraganglion cells. The characteristic feature of this tumor is a rich vascular network in its contents and

Correspondence to: Professor Kiyoto Shiga, Department of Head and Neck Surgery, Iwate Medical University School of Medicine, 19-1 Uchimaru, Morioka, Iwate 020-8505, Japan

E-mail:kshiga@iwate-med.ac.jp

Key words: carotid body tumor, Japan, multi-institutional survey, family history, paraganglioma, surgery, blood loss and operation time, preoperative embolization of the feeding artery capsules supplied by many feeding arteries (1). As the risk of complications such as cranial nerve paralysis increases as the tumor grows, surgical resection is recommended for all CBTs in otherwise healthy patients $(2,3)$. Moreover, there is a small but definite risk of malignancies for all paragangliomas (4-7). Molecular biological study has so far revealed that this tumor has various types of gene alterations such as point mutations in the SDH gene family $(2,8,9)$. A total of 10 to $35 \%$ of patients with CBT are estimated to harbor a hereditary predisposition and SDHD is the most common mutation, followed by SDHB and then SDHC (2). In one review, it was reported that SDH germ-line mutations are present in $31 \%$ of patients with head and neck paragangliomas (10). The concept of the 'hereditary paraganglioma-pheochromocytoma syndrome' has arisen to describe familial paraganglioma patients, which includes CBT patients with a family history and gene alterations (11-13).

The low incidence rate of this tumor and absence of a registration and study system has prevented detailed research to be performed to clarify the present status of this tumor in Japan. Also the status of SDHx gene mutations was not obvious because of genetic testing was not performed for these patients. We organized a study group, which we call the Japan Carotid Body Tumor Research Group (JCBTRG), and initiated a survey of the patients with CBT in Japan. The goal of our study is to reveal the overall aspects of gene alteration patterns, such as those present in the SDH gene family, among patients in Japan. Initially, we began with a survey of the status of patients throughout Japan. Here we report the characteristic features of CBT patients in Japan unveiled from our studies.

\section{Patients and methods}

All procedures followed were in accordance with the ethical standards of the responsible committee on human experimentation (institutional and national) and with the Helsinki Declaration of 1975, as revised in 2008.

The study design was a multi-institutional retrospective review of medical records. Research protocols were assessed 
and accepted by the institutional research boards of individual institutions.

We sent the research format for cases of CBT to 635 authorized institutions that had specialists who were members of the Japan Otolaryngology Society. A total of 316 responses were sent back to the research bureau at Iwate Medical University and 150 patients were registered from 25 institutions in our study. There were 204 hospitals or institutions that did not have CBT patients for 20 years. Information on the CBT patients was summarized and analyzed. The analyzed items were gender, age, family history, size, Shamblin classification (Fig. 1) (1), location of the patients, operation time of extirpation surgery, amount of blood loss, preoperative embolization of the feeding arteries and resection and repair of the carotid arteries. Statistical analyses were carried out using Students' t-test.

\section{Results}

From 1995 to 2015, 399 patients with CBT were referred to 112 institutions. In summary, 194 patients underwent surgery and 205 patients were under follow-up without surgery. Patients with CBT from these institutions were registered in our study and we obtained 150 summarized patient records from 25 institutions. There were 87 females and 63 males and their mean and median age were 48.0 years old and 49 years old, respectively, ranging from 8 to 78 years old (Fig. 2). Fifty to 60 year old patients were the most dominant throughout all age groups followed by 40 to 50 year old patients. There was an 8 year old patient as well. As for gender, female patients were dominant in almost every age group. Fifteen patients had bilateral CBTs resulting in 165 CBTs.

The chief complaints of the patients with CBT are shown in Table I. Neck tumors were the most frequent chief complaint in these patients and 125 patients $(83.3 \%)$ complained of neck tumors. The second chief complaint was an incidental recognition of the tumor by some modalities such as CT scan or MRI (14 patients, 9.3\%). There were some patients who complained of hoarseness (3 patients, 2.0\%), pharyngeal discomfort (2 patients, $1.3 \%$ ) dysphagia, hearing loss, numbness of the body, or chest discomfort. Four patients (2.7\%) complained of pain. The mean and median suffering period was 46.1 months and 10.5 months, respectively, ranging from 0 months to 480 months.

Eighteen patients had a family history of paragangliomas (Table II). There were 10 male and 8 female patients. Five patients had fathers who had a type of paraganglioma; namely, CBT, vagal paraganglioma, or pheochromocytoma (Cases 1, 3, 5, 6 and 12) and the other 4 patients had a father who was expected to have a type of paraganglioma (Cases 2 , 10, 14 and 17). Two patients had a brother and a sister with paragangliomas and two patients had a brother and a sister who were assumed to have paragangliomas. A patient had sons with paragangliomas and two patients had a daughter with CBT. Two patients had bilateral CBTs.

Seven patients had metastases that included the lymph nodes in 5 patients and the lung in 3 patients. As for other paragangliomas, 4 patients had pheochromocytomas, two of which were malignant. Two of these patients had a family
Table I. Chief complaint in the 150 patients with carotid body tumors.

\begin{tabular}{lcc}
\hline Complaint type & $\begin{array}{r}\text { Number of } \\
\text { the patients }\end{array}$ & $\begin{array}{c}\text { Percentage of total } \\
\text { patients (\%) }\end{array}$ \\
\hline Neck tumor & 125 & 83.3 \\
Incidental recognition & 14 & 9.3 \\
Pain & 4 & 2.7 \\
Hoarseness & 3 & 2.0 \\
Pharyngeal discomfort & 1 & 0.6 \\
Dysphagia & 1 & 0.6 \\
Hearing loss & 1 & 0.6 \\
Numbness of the body & 1 & 0.6 \\
Chest discomfort & 1 & 0.6 \\
\hline
\end{tabular}

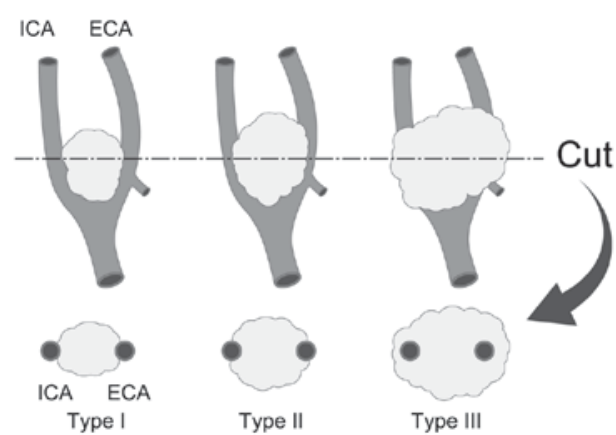

Figure 1. Shamblin classification. Typical appearance of Shamblin type I, II and III tumors are shown and their association with carotid arteries has been indicated. Type I tumors are localized within the carotid arteries. Type II tumors partially adhere to or surround the carotid arteries. Type III tumors completely surround at least one of the carotid arteries. ICA, internal carotid artery; ECA, external carotid artery.

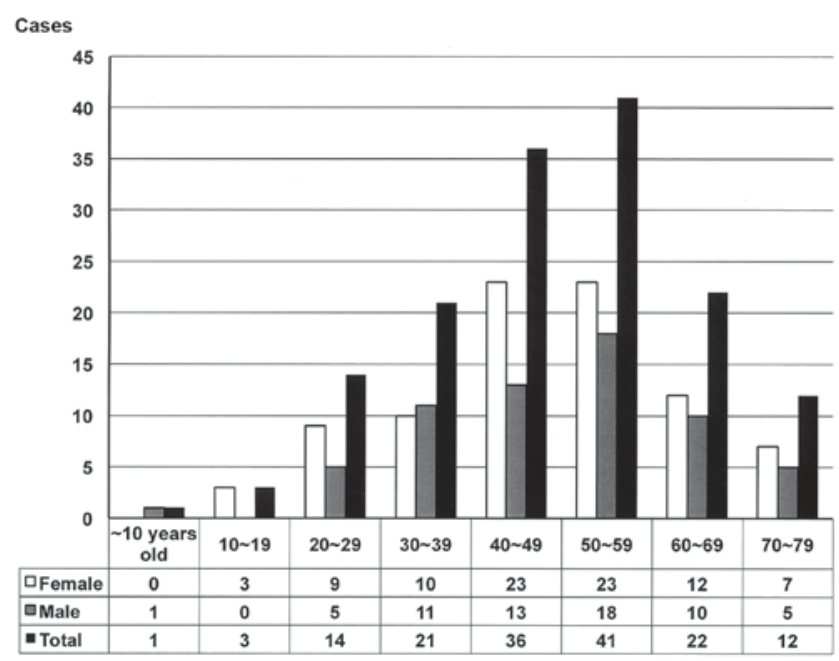

Figure 2. Age and gender distribution of patients with carotid body tumors in Japan. The mean and median age of the patients were 48.0 and 49 years old, respectively.

history. Three patients had glomus tumors and 2 patients had mediastinal paragangliomas. One patient had von Hippel Lindau disease. 
Table II. Family history of patients with CBT.

\begin{tabular}{ccll}
\hline Case no. & Age (years) & Gender & \\
\hline 1 & 30 & Male & Father: CBT+vagal paraganglioma Aunt: CBT \\
2 & 23 & Female & Father: Renal tumor (pheochromocytoma?) \\
3 & 40 & Female & Father: Pheochromocytoma elder brother: Pheochromocytoma \\
4 & 56 & Female & Younger brother: Vagal paraganglioma \\
5 & 40 & Male & Father: CBT elder brother: CBT \\
6 & 45 & Male & Father: CBT younger brother: CBT \\
7 & 72 & Male & Sons: CBT \\
8 & 49 & Male & Daughter: CBT \\
9 & 53 & Male & Elder sister: Glomus tumor paternal cousin: Glomus tumor \\
10 & 48 & Female & Father: Bilateral tumor of the neck(CBT?) \\
11 & 37 & Male & Details unknown \\
12 & 29 & Female & Father: CBT \\
13 & 56 & Male & Daughter: CBT \\
14 & 51 & Male & Father: Details unknown \\
15 & 59 & Male & Younger sister: Details unknown \\
16 & 58 & Female & Elder brother: Details unknown \\
17 & 42 & Female & Father: Details unknown \\
18 & 19 & Female & Grandmother: Details unknown \\
\hline
\end{tabular}

Cases 5, 6 and 7 were relatives, and cases 12 and 13 were relatives. CBT, carotid body tumor.

Although the survey covered all prefectures, there were some tendencies that indicated the frequency of CBT was dependent on the area where the patients lived or the hospitals to which they were referred. Table III shows the frequencies of CBT patients according to the institutions to which they were referred. There were 28 prefectures that had no patient with CBT registered in our study. The other 19 prefectures had more than one patient registered to our study. One-third of the patients (57 patients) were located in the Tokyo area where medical institutions were gathered. Fifteen patients were registered from Aichi and Hyogo. Eleven and ten patients were from Iwate and Miyagi, respectively. Nine patients were from Hokkaido and Nagasaki, respectively.

Ninety-four patients underwent surgery and 6 patients underwent radiation therapy. The other patients remained under observation because of the patients' choice or physicians' recommendation. The treatment choice of these patients depended on the institutions to which they were referred.

Among the 94 patients including 4 patients with bilateral CBTs who underwent surgery to remove a CBT, 23 patients had tumors classified as Shamblin type I, 59 had type II and 12 had type III (Table IV). Classification of tumors from four patients were not recorded nor undone. The feeding arteries of 76 tumors were preoperatively embolized before resection of the CBT (Table IV). The average tumor size in diameter was $26.3 \mathrm{~mm}$ in Shamblin type I tumors, $37.3 \mathrm{~mm}$ in type II tumors and $36.7 \mathrm{~mm}$ in type III tumors.

We analyzed the relationship between operation time of the surgery and the amount of blood loss. Fig. 3 shows the result of the analysis. The calculated coefficient correlation was 0.69 for all patients. According to Shamblin classification, mean operation time of the surgery and the
Table III. Location of patients with carotid body tumors in Japan.

\begin{tabular}{lrrr}
\hline Prefecture & Male & Female & Total \\
\hline Hokkaido & 4 & 5 & 9 \\
Iwate & 3 & 8 & 11 \\
Miyagi & 5 & 5 & 10 \\
Fukushima & 0 & 1 & 1 \\
Saitama & 0 & 3 & 3 \\
Chiba & 0 & 1 & 1 \\
Tokyo & 20 & 37 & 57 \\
Kanagawa & 2 & 0 & 2 \\
Niigata & 2 & 2 & 4 \\
Fukui & 1 & 0 & 1 \\
Aichi & 6 & 9 & 15 \\
Mie & 1 & 2 & 3 \\
Hyougo & 7 & 8 & 15 \\
Nara & 0 & 2 & 2 \\
Hiroshima & 0 & 2 & 2 \\
Fukuoka & 1 & 0 & 1 \\
Nagasaki & 7 & 2 & 9 \\
Kumamoto & 2 & 0 & 2 \\
Okinawa & 2 & 0 & 2 \\
Total no. of patients & 63 & 87 & 150 \\
\hline
\end{tabular}

mean amount of blood loss were $229 \mathrm{~min}$ and $77.8 \mathrm{ml}$ in Shamblin I, $262 \mathrm{~min}$ and $229 \mathrm{ml}$ in Shamblin II, $461 \mathrm{~min}$ and $404 \mathrm{ml}$ in Shamblin III, respectively. As for operation 
Table IV. Shamblin classification.

$\mathrm{A}$, Size in diameter $(\mathrm{mm})$

\begin{tabular}{lcccc}
\hline & \multicolumn{3}{c}{ Shamblin classification } & \\
\cline { 2 - 4 } Variable & I & II & III & Average \\
\hline Mean & 26.3 & 37.3 & 36.7 & 34.6 \\
Median & 24.5 & 38.0 & 35.5 & 35.0 \\
\hline
\end{tabular}

B, Preoperative embolization (n)

\begin{tabular}{lrrrr}
\hline & \multicolumn{3}{c}{ Shamblin classification } & \\
\cline { 2 - 4 } Variable & \multicolumn{1}{c}{ I } & II & III & Total \\
\hline+ & 19 & 48 & 9 & 76 \\
- & 4 & 11 & 3 & 18 \\
Total (n) & 23 & 59 & 12 & 94 \\
\hline
\end{tabular}

A total of 94 patients, including 4 patients with bilateral carotid body tumors, underwent surgery. Classification of the tumors from 4 patients were not recorded/performed.

time, there were significant differences between Shamblin I and II $(\mathrm{P}=0.016)$ and Shamblin I and III $(\mathrm{P}<0.001)($ Table V). While as for the amount of blood loss, there were significant differences between Shamblin I and III $(\mathrm{P}<0.001)$ and Shamblin II and III $(\mathrm{P}<0.001)$ (Table V).

Table VI shows the main feeding arteries of 78 tumors detected by carotid arteriography. Most frequent feeding artery was the ascending pharyngeal artery followed by the superior thyroid artery and the occipital artery. It is noteworthy that in some patients, feeding artery was derived from external carotid artery $(n=7)$ and internal carotid artery $(n=1)$.

When the patients underwent preoperative embolization, mean operation time of the surgery and the mean amount of blood loss were $240 \mathrm{~min}$ and $55.9 \mathrm{ml}$ in Shamblin I, $255 \mathrm{~min}$ and $178 \mathrm{ml}$ in Shamblin II, $468 \mathrm{~min}$ and $406 \mathrm{ml}$ in Shamblin III, respectively. While the patients did not undergo preoperative embolization, mean operation time of the surgery and the mean amount of blood loss were $181 \mathrm{~min}$ and $171 \mathrm{ml}$ in Shamblin I, $290 \mathrm{~min}$ and $468 \mathrm{ml}$ in Shamblin II, $440 \mathrm{~min}$ and $396 \mathrm{ml}$ in Shamblin III, respectively. As for the amount of blood loss, there was a significant difference between the patients with preoperative embolization and those without that in Shamblin I and II tumors (Table VII, P=0.038 and $\mathrm{P}=0.0011$, respectively).

Patients with Shamblin I tumor underwent no resection of carotid artery. Twenty-one out of 59 patients with Shamblin II tumor underwent resection of external carotid artery (ECA) and 2 patients underwent reconstruction of internal carotid artery (ICA), while all 12 patients with Shamblin III tumor underwent resection of ECA and 10 patients underwent reconstruction of ICA (Table VIII).

Fifty-five $(56 \%)$ patients who underwent surgery exhibited some postoperative complications (Table IX). The most frequent complication was vagal nerve paralysis, including
Table V. Blood loss and operation time by Shamblin classification.

\begin{tabular}{|c|c|c|c|c|}
\hline Variable & Shamblir & ambli & mbli & I P-value \\
\hline $\begin{array}{l}\text { Mean blood } \\
\text { loss }(\mathrm{ml})\end{array}$ & 78 & 229 & 404 & $\begin{array}{c}\text { I vs. II: } \\
0.016 \\
\text { II vs. III: } \\
0.082 \\
\text { I vs. III: } \\
<0.001\end{array}$ \\
\hline $\begin{array}{l}\text { Mean operation } \\
\text { time }(\mathrm{min})\end{array}$ & 229 & 262 & 461 & $\begin{array}{c}\text { I vs. II: } \\
0.40 \\
\text { II vs. III: } \\
<0.001 \\
\text { I vs. III: } \\
<0.001\end{array}$ \\
\hline
\end{tabular}

Table VI. Main feeding arteries of carotid body tumors.

Feeding artery Number of the patients (\%)

\begin{tabular}{lc}
\hline Ascending pharyngeal artery & $50(64.1)$ \\
Superior thyroid artery & $18(23.1)$ \\
Occipital artery & $17(21.8)$ \\
External carotid artery & $7(9.0)$ \\
Lingual artery & $6(7.7)$ \\
Posterior auricular artery & $4(5.1)$ \\
Facial artery & $2(2.6)$ \\
Ascending palatine artery & $2(2.6)$ \\
Superficial temporal artery & $1(1.3)$ \\
Common carotid artery & $1(1.3)$ \\
Internal carotid artery & $1(1.3)$
\end{tabular}

Cases that included multiple main feeding arteries have also been indicated in this table.

recurrent nerve palsy in $22(23 \%)$ patients, followed by hypoglossal nerve paralysis in 18 (19\%). Thirteen patients exhibited two or more nerve paralysis episodes; the most frequent combination was that of vagal and hypoglossal nerve paralysis. Most of these complications were transient, but a patient underwent phonosurgery afterwards. There was no mortality in this cohort of patients after surgery.

\section{Discussion}

As it is well known that CBTs are very rare, detailed features of this tumor have not been clarified in Japan. One of the reasons is that there has been no registration and study system until we organized the study group JCBTRG and initiated the survey of patients with CBT. By recruiting CBT patients to our survey from 635 authorized institutions for specialists of the Japan Otolaryngology Society, we could include CBT patients from throughout Japan as a whole even if some of the patients were not registered in our research system. 
Table VII. Operation time and blood loss during surgery with or without preoperative embolization.

A, Operation time

\begin{tabular}{lcccr}
\hline Shamblin classification & Total time (min) & Embolization (-) & Embolization (+) & P-value \\
\hline I & $229 \pm 97$ & $240 \pm 102$ & $181 \pm 38$ & 0.317 \\
II & $262 \pm 138$ & $255 \pm 123$ & $290 \pm 183$ & 0.496 \\
III & $461 \pm 115$ & $468 \pm 104$ & $440 \pm 139$ & 0.524 \\
\hline
\end{tabular}

$\mathrm{B}$, Blood loss during surgery

\begin{tabular}{|c|c|c|c|c|}
\hline Shamblin classification & Total quantity (ml) & Embolization (-) & Embolization (+) & P-value \\
\hline I & $78 \pm 114$ & $56 \pm 45$ & $171 \pm 226$ & 0.038 \\
\hline II & $229 \pm 271$ & $178 \pm 206$ & $468 \pm 387$ & 0.0011 \\
\hline III & $404 \pm 203$ & $406 \pm 218$ & $396 \pm 147$ & 0.623 \\
\hline
\end{tabular}

Data are presented as the mean \pm standard deviation.

Table VIII. Damage and repair to the carotid arteries.

\begin{tabular}{lrrrc}
\hline \multicolumn{5}{c}{ Shamblin Shamblin Shamblin } \\
Variable & I & II & III & Total \\
\hline Number of patients & 23 & 59 & 12 & 94 \\
Resection of ECA & 0 & 21 & 12 & $33(33.7 \%)$ \\
Reconstruction of & 0 & 2 & 10 & $12(12.2 \%)$ \\
ICA & & & & \\
\hline
\end{tabular}

Four tumors were not classified and were omitted from this table. ECA, external carotid artery; ICA, internal carotid artery.

In accordance with our expectations, the number of female CBT patients was more than that of male patients. Although Shamblin's reports showed that the number of male patients was twice as many as that of female patients (1), most reports have shown that the number of female patients was more than that of male patients $(3,13-16)$.

The most common chief complaint in our patients was neck tumors and $83.3 \%$ of the patients complained of a neck tumor. As expected, their suffering periods were relatively long compared to those of other neck tumors, especially malignant ones. The longest suffering period was 40 years, indicating CBT has a characteristic feature of being a slow growing neck mass because most CBTs are benign. As some patients showed paralysis of the vagal nerve, which led to symptoms such as hoarseness and dysphagia, physicians must treat CBT neck tumors when they recognize vagal nerve paralysis as a differential diagnosis.

Eighteen patients (12\%) had a family history of some kind of paraganglioma. This frequency was compatible with previous reports $(12,17,18)$. Perhaps on-going analysis of gene mutations and clarification of gene mutation status could lead to recognition of more family members in Japanese CBT patients. In fact, a father and a daughter from Miyagi prefecture had the same mutation in the SDHD gene (18). Similar results were reported from Korea and China $(19,20)$.

Seven patients $(4.7 \%)$ had metastases of CBT and their tumor was diagnosed as a malignant CBT. This frequency was compatible with previous reports $(4-7,21)$. It is well known that, as histopathological examination cannot distinguish a malignant tumor by morphological features in microscopic findings, malignancy or not is diagnosed by metastatic activity, namely clinical findings. The necessity of surgical resection depends on this aspect of tumor malignancy if it is not frequent. Head and neck surgeons must consider surgical resection of CBT once a patient is referred to our hospital.

The uneven distribution of the CBT patients is perhaps reflected in the uneven distribution of the population and medical institutions in Japan. Tokyo is the capital city of Japan and her population is over 10,000,000. However, as Japan has a population of approximately $120,000,000$, it is not reasonable to expect that one-third of the CBT patients would be from the Tokyo area. Maybe the number of medical institutions also influenced the majority of patients being from the Tokyo area. Although Aichi and Hyogo have reasonable population sizes for the number of CBT patients, Iwate, Miyagi and Nagasaki have smaller populations, which were not reasonable for the number of their CBT patients. As we previously reported (18), CBT patients in Miyagi and Iwate (next to Miyagi) have the possibility of having the same gene alterations. These results indicated the possibility that some gene alterations penetrated into other areas in Japan such as Miyagi, Iwate and Nagasaki. Further investigation is needed to clarify the gene alterations of CBT patients in these high incidence areas.

As the characteristic feature of this tumor is a rich vascular network in its contents and capsules supplied by many feeding arteries, surgeons must be extremely careful to resect CBT because careless procedures result in vessel damage and much blood loss, especially damage of carotid artery lead to reconstruction of it. Preoperative angiography revealed that the most frequent feeding artery was the ascending pharyngeal artery followed by the occipital artery 
Table IX. Postoperative complications following carotid body tumor surgery.

\begin{tabular}{lccc}
\hline Postoperative complication & Total number & Embolization (-) & Embolization (+) \\
\hline X paralysis & 22 & 4 & 18 \\
XII paralysis & 18 & 5 & 13 \\
First bite syndrome & 10 & 0 & 10 \\
Horner syndrome & 7 & 0 & 5 \\
IX paralysis & 6 & 1 & 4 \\
VII marginal branch paralysis & 4 & 0 & 4 \\
Dysphagia & 4 & 0 & 1 \\
XI paralysis & 1 & 1 & 0 \\
Hypertension & 1 & 0 & 1 \\
Orthostatic hypotension & 1 & 1 & 0 \\
Tunnel vision & 1 & 0 & 1 \\
Vertigo & 1 & 0 & 0 \\
Carotid artery stenosis & 1 & 1 & 46 out of 76 patients \\
Cerebral infarction & 1 & 9 out of 18 patients \\
Total no. of cases & 55 out of 94 patients & & \\
\end{tabular}

There was no significant difference in the prevalence of these complications between the 2 groups of patients.

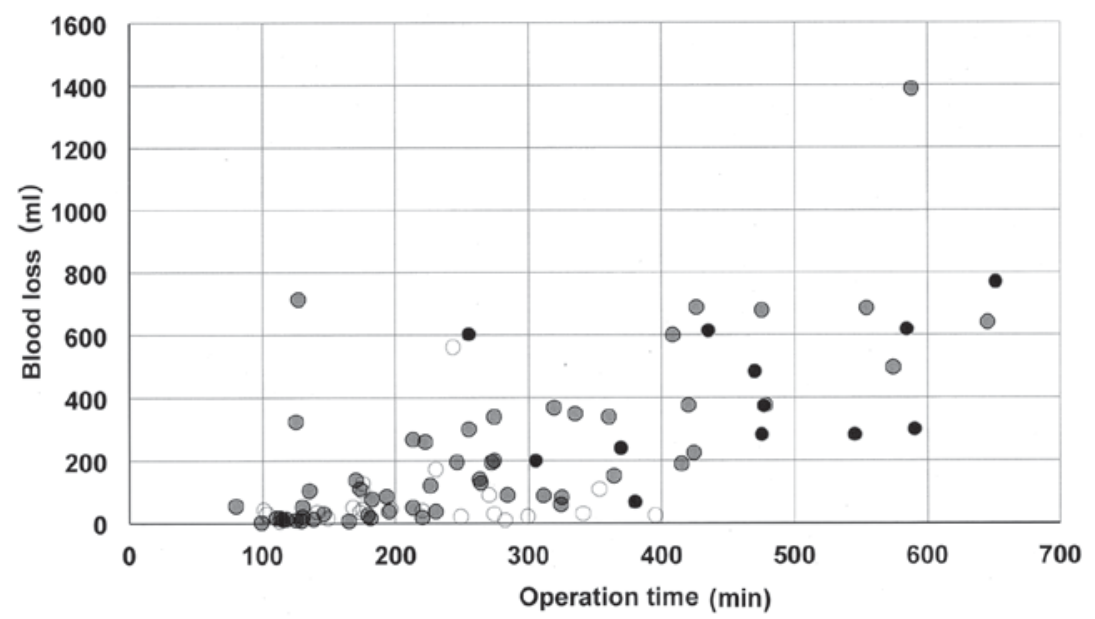

Figure 3. Distribution of blood loss and operation duration of surgery for carotid body tumors. Shamblin type I, II and III tumors are indicated by open circles, gray circles and closed circles, respectively. The x-axis indicates the operation time ( $\mathrm{min})$ and the $\mathrm{y}$-axis indicates the amount of blood loss (ml).

and the superior thyroid artery. Our result indicated that the direct feeding arteries derived from external carotid artery were relatively common, if not so many, in CBT patients $(9 \%$, 7 out of 78 tumors, Table VI). Perhaps these direct feeding arteries from carotid arteries were ringleaders for much blood loss in surgery. As we head and neck surgeons experienced few cases of extra-branches from carotid artery during neck surgery, especially neck dissection, these frequent direct branches from carotid arteries could reflect embryonic origin of branches of hereditary paraganglioma patients. As there have been few studies to report the distribution of feeding arteries into CBT, this study give the light for head and neck surgeons and interventional radiologists to deal with feeding arteries of CBT.

As our expectations, time of the surgery and the amount of blood loss depended on Shamblin classification. Shamblin III tumors took more time and blood loss than Shamblin II and I tumors during their resection surgery, while Shamblin II tumors took more time and blood loss than Shamblin I tumors (Table IV). Although effect of preoperative embolization to reduce the amount of blood loss was seen in Shamblin I and II tumors, effectiveness for reduction of time of the surgery was not obvious in our series of patients (Table V), As same results were reported by Power et al (22), it would be common that the reduction of operative time is difficult by preoperative embolization in CBT surgery. It could also be likely that the variety of embolization technique and interventional radiologists made the evaluation difficult. Multi-institutional study using standard technique must be needed to clarify the effect of preoperative embolization for accurate evaluation of the procedures.

As Shamblin III tumor surrounded ECA and ICA, resection surgery for these tumors needed resection these arteries 
to some extent. Actually all patients with Shamblin III tumor underwent resection of ECA and $83 \%$ of these patients (10 out of 12) underwent reconstruction of ICA in our series. Although same results were reported by some authors (23), there were few reports which mentioned about the correlation of ICA reconstruction and Shamblin III tumor. Our results indicated that preparation of reconstruction surgery of ICA must be needed to perform resection of Shamblin III CBTs.

As we performed a survey of the status of patients throughout Japan, we can report the characteristic features of CBT patients in Japan as found in our studies. There were some high-incidence areas of CBT such as Miyagi, Iwate, and Nagasaki, perhaps reflecting the prevalence of patients with a familial history of paraganglioma with some gene alterations. Among the 94 patients who underwent surgery to remove a CBT, 23 patients presented with tumors classified as Shamblin type I, 59 with type II, and 12 with type III. The most frequent feeding artery of these CBTs was the ascending pharyngeal artery. Preoperative embolization of these feeding arteries was effective to reduce blood loss, but not the operation time of Shamblin type I and II tumors.

\section{Acknowledgements}

This work was supported by a Grant-in-aid for JSPS KAKENHI (grant no. 26462619). The abstract of the present study was published in J Clin Oncol 35 (Suppl 15): e17574, 2017.

\section{References}

1. Shamblin WR, ReMine WH, Sheps SG and Harrison EG Jr: Carotid body tumor (Chemodectoma), Clinicopathologic analysis of ninety cases. Am J Surg 122: 732-739, 1971.

2. Fruhmann J, Geigl JB, Konstantiniuk P and Cohnert TU: Paraganglioma of the carotid body: Treatment strategy and SDH-gene mutations. Eur Vasc Endovasc Surg 45: 431-436, 2013

3. Sajid MS, Hamilton G and Baker DM: A multicenter review of carotid body tumor management. Eur J Vasc Endovasc Surg 34: 127-130, 2007.

4. Lee JH, Barich F, Karnell LH, Robinson RA, Zhen WK, Gantz BJ and Hoffman HT; American College of Surgeons Commission on Cancer; American Cancer Society: National cancer data base report on malignant paragangliomas of the head and neck. Cancer 94: 730-737, 2002.

5. Zhang WC, Cheng JP, Li Q, Zhang L, Wang XD and Anniko M: Clinical and pathological analysis of malignant carotid body tumor: A report of nine cases. Acta Otolaryngol 129: 1320-1325, 2009.

6. Hall TC, Renwick P and Stafford ND: Recurrent familial malignant carotid body tumour presenting with lymph node metastasis: Case report and review of diagnosis and management of familial carotid body tumours. J Laryngol Otol 124: 1344-1346, 2010.

7. Nishijima H, Asakage T and Sugasawa M: Malignant carotid body tumor with systemic metastases. Ann Otol Rhinol Lalyngol 120: 381-385, 2011
8. Offergeld C, Brase C, Yaremchuk S, Mader I, Rischke HC, Gläsker S, Schmid KW, Wiech T, Preuss SF, Suárez C, et al: Head and neck paragangliomas: Clinical and molecular genetic classification. Clinics(Sao Paulo) 67 (Suppl 1): S19-S28, 2012.

9. Burnichon N, Rohmer V, Amar L, Herman P, Leboulleux S, Darrouzet V, Niccoli P, Gaillard D, Chabrier G, Chabolle F, et al: The succinate dehydrogenase genetic testing in a large prospective series of patients with Paragangliomas. J Clin Endocrinol Metab 94: 2817-2827, 2009.

10. Neumann HP, Erlic Z, Boedeker CC, Rybicki LA, Robleda M, Hermsen M, Schiavi F, Falcioni M, Kwok P, Bauters C, et al: Clinical predictors for germline mutations. in head and neck paraganglioma patients: Cost reduction strategy in genetic diagnostic process as fall-out. Cancer Res 69: 3650-3656, 2009.

11. Astuti D, Latif F, Dallolv A, Dahia PL, Douglas F, George E, Sköldberg F, Husebye ES, Eng C and Maher ER: Gene mutations in the succinate dehydrogenase subunit SDHB cause susceptibility to familial pheochromocytoma and to familial paraganglioma. Am J Hum Genet 69: 49-54, 2001.

12. Kirmani S and Young WF: Hereditary ParagangliomaPheochromocytoma Syndromes. Gene Reviews. In: Source GeneReviews ${ }^{\circledR}$ [Internet]. Adam MP, Ardinger HH, Pagon RA, Wallace SE, Bean LJH, Mefford HC, Stephens K, Amemiya A, Ledbetter N (eds). University of Washington, Seattle, 2008 (updated Nov 6, 2014).

13. Unlü Y, Becit N, Ceviz M and Koçak H: Management of carotid body tumors and familial paragangliomas: Review of 30 years' experience. Ann Vasc Surg 23: 616-620, 2009.

14. O'Neill S, O'Donnell M, Harkin D, Loughrey M, Lee B and Blair P: A 22-year northern Irish experience of carotid body tumours. Ulster Med J 80: 133-140, 2011.

15. Nazari I, Moghaddam FA, Zamani MM and Salimi J: Clinical characteristics and remedies in 45 Iranians with carotid body tumors. Acta Med Iran 50: 339-343, 2012.

16. Luna-Ortiz K, Rascon-Ortiz M, Villavicencio-Valencia V, Granados-Garcia M and Herrera-Gomez A: Carotid body tumors: Review of a 20-year experience. Oral Oncol 41: 56-61, 2005.

17. Sridhara SK, Yener M, Hnna EY, Rich T, Jimenez C and Kupferman ME: Genetic testing in head and neck paraganglioma: Who, what and why? J Neurol Surg B Skull Base 74: 236-240, 2013.

18. Ogawa K, Shiga K, Saijo S, Ogawa T, Kimura N and Horii A: A novel G106D alteration of the SDHD gene in a pedigree with familial paraganglioma. Am J Med Genet A 140: 2441-2446, 2006.

19. Kim ES, Kim SY, Mo EY, Jang DK, Moon SD and Han JH: Novel germline SDHD mutation in a patient with recurrent familial carotid body tumor and concomitant pheochromocytoma. Head neck 36: E131-E135, 2014.

20. Wang CP, Chen TC, Chang YL, Ko JY, Yang TL, Lo FY, Hu YL, Chen PL, Wu CC and Lou PJ: Common genetic mutations in the start codon of the SDH subunit D gene among Chinese families with familial head and neck paragangliomas. Oral Oncol 48: 125-129, 2012.

21. Kupferman ME and Hanna EY: Paragangliomas of the head and neck. Curr Oncol Rep 10: 156-161, 2008.

22. Power AH, Bower TC, Kasperbauer J, Link MJ, Oderich G, Cloft H, Young WF Jr and Gloviczki P: Impact of preoperative embolization on outcomes of carotid body tumor resections. J Vasc Surg 56: 979-989, 2012.

23. Torrealba JI, Valdés F, Krämer AH, Mertens R, Bergoeing M and Mariné L: Management of carotid bifurcation tumors: 30-year experience. Ann Vasc Surg 34: 200-205, 2016. 